http://periodicos.uefs.br/index.php/acordasletras/index http://dx.doi.org/10.13102/cl.v20i2.4946

\title{
O ENADE e a formação do professor de literatura
}

\author{
ENADE and the literature teacher training
}

\author{
Andréia da Cunha Malheiros Santana* \\ Universidade Estadual de Londrina \\ Londrina, Paraná, Brasil \\ Sheila Oliveira Lima** \\ Universidade Estadual de Londrina \\ Londrina, Paraná, Brasil
}

\begin{abstract}
Resumo: Este artigo tem como principal objetivo compreender como o ENADE (Exame Nacional de Desempenho de Estudantes) avalia a formação dos professores na área de leitura e literatura e os efeitos disso nos currículos dos cursos de licenciatura em Letras. Tendo em vista esse objetivo, a pesquisa busca identificar as questões que envolvem a temática da leitura e da literatura nos exames realizados nos anos de 2005, 2008, 2011 e 2014. Parte-se da premissa de que o modo como o ENADE aborda a leitura e a literatura influencia os cursos de formação de professores, desta forma interfere no próprio ensino destes conteúdos. Trata-se de uma pesquisa mista, que articula dados quantitativos com dados qualitativos. A fundamentação teórica articulou as leituras de diferentes temas como a legislação (DCN e SINAES), o controle exercido pela avaliação externa (Madaus, Scaramucci) e autores que trabalham com a literatura e o seu ensino (Candido, Jouve, Colomer). Como conclusão, foi possível destacar que o exame também precisa ser avaliado, pois tem ultrapassado os objetivos para os quais foi criado, na medida em que vem realizando uma seleção curricular de alguns conhecimentos e privilegiando alguns temas em detrimento de outros, o que interfere negativamente na formação de professores.
\end{abstract}

Palavras-chave: ENADE. Literatura. Currículo. Formação docente.

\begin{abstract}
This paper aims to understand how the ENADE (National Student Performance Exam) evaluates the training of teachers in the area of reading and Literature and the effects on the curriculum of undergraduate Letters. In view of this objective, the research seeks to identify the issues surrounding the theme of reading and Literature in the exams conducted in 2005, 2008, 2011 and 2014. It is based on the premise that the way ENADE approaches reading and Literature influences teacher training courses, thus interfering with the teaching of these contents. This is a qualitative-quantitative research, because it articulates quantitative data with qualitative explanation. The theoretical basis articulated the readings of different topics such as legislation (DCN and SINAES), the control exercised by external evaluation (Madaus, Scaramucci) and authors who work with Literature and its teaching (Candido, Jouve, Colomer). In conclusion, it was possible to highlight that the exam also needs to be evaluated, as it has exceeded the objectives for which it was created, as it has been conducting a curricular selection of some knowledge and privileging some subjects over others, which interferes negatively in teacher training.
\end{abstract}

Keywords: ENADE. Literature. Curriculum. Teacher training.

\footnotetext{
* Doutora em Educação Escolar. Docente do Departamento de Letras Vernáculas e Clássicas do CLCH da UEL. Membro permanente dos programas de pós-graduação PPEDU-UEL e ProfletrasUEL. E-mail: andreiacunhamalheiros@gmail.com.

** Doutora em Linguagem e Educação. Docente do Departamento de Letras Vernáculas e Clássicas do CLCH da UEL. Membro permanente dos programas de pós-graduação PPGEL-UEL e ProfletrasUEL.E-mail: sheilaol@uol.com.br.
} 


\section{INTRODUÇÃO}

Para compreender melhor os conhecimentos cobrados no ENADE (Exame Nacional de Desempenho de Estudantes) e o seu impacto na formação de professores, é necessário retomar os objetivos do próprio exame. Ele é parte do SINAES (Sistema Nacional de Avaliação da Educação Superior), que foi instituído em 2004 pela lei 10.861 (BRASIL, 2004) e é composto por 3 avaliações. O ENADE é apenas uma delas, mas acabou ganhando mais espaço do que as demais, o que não corresponde à ideia inicial.

Esse crescimento desproporcional da importância do ENADE em relação aos demais instrumentos do SINAES se deve, principalmente, à importância atribuída ao exame no cenário educacional brasileiro.

A avaliação externa, atualmente, apresenta-se como uma política pública de Estado e está atrelada à política adotada por cada sociedade. Para Afonso (2009), as "[...] as funções da avaliação têm que ser [...] compreendidas no contexto das mudanças educacionais e das mudanças econômicas e políticas mais amplas [...] a avaliação é ela própria uma atividade política" (AFONSO, 2009, p. 19) e, por isso, gera efeitos políticos, como a valorização de um currículo em detrimento de outro, o que, ao nosso ver, influencia a formação dos professores.

A avaliação está sempre atrelada a um currículo e ao tipo de sociedade que a dissemina. Para Madaus (1988), a avaliação externa é, sobretudo, uma forma de controle sobre o que é ensinado nas instituições de ensino. Corroborando com Madaus, Scaramucci (2004) afirma que não é possível negar o efeito retroativo dessas avaliações externas, pois elas acabam interferindo no currículo do nível de ensino que a antecede. Para a autora, há muito tempo, destinado aos conteúdos abordados nestas avaliações e pouco para trabalhar com os conhecimentos que não foram incorporados a ela. Tal constatação já foi feita por Stecher (2002), para ele o estreitamento do currículo tem um efeito negativo para a formação dos estudantes/licenciandos. No caso do ENADE, a formação de professores seria moldada/influenciada por esta avaliação.

O ENADE está atrelado às DCNs (Diretrizes Curriculares Nacionais) (BRASIL, 2001) que orientam o currículo dos cursos de graduação. Tais diretrizes apresentam, em linhas gerais, quais os eixos sobre os quais o currículo deve estar apoiado - estudos linguísticos e literários -, porém sem detalhar nenhuma concepção teórica. Aparentemente, o fato de não detalhar o que deve ser trabalhado contribui para a autonomia das instituições de ensino, o que não é inteiramente verdade, uma vez que o ENADE exige um conhecimento específico dos licenciandos.

Para melhor compreender o exame e os conhecimentos por ele cobrados, as questões foram divididas em três temáticas, que foram instituídas a partir da leitura das DCN: esfera linguística, esfera literária e esfera de formação pedagógica. Consideramos pertencentes à esfera linguística aquelas questões que trabalham com análises gramaticais de diferentes níveis, bem como aquelas relativas à linguística e à produção de texto. Consideramos pertencentes à esfera literária aquelas questões que 
buscam checar o conhecimento dos graduandos sobre a leitura e a interpretação de texto, bem como sobre as diferentes correntes literárias e a contribuição dos diversos autores na formação da nossa cultura letrada. Por fim, julgamos pertencentes à esfera da formação pedagógica aquelas questões diretamente ligadas à prática do professor e ao exercício do magistério.

Gráfico 1. Distribuição dos conhecimentos cobrados nos exames.

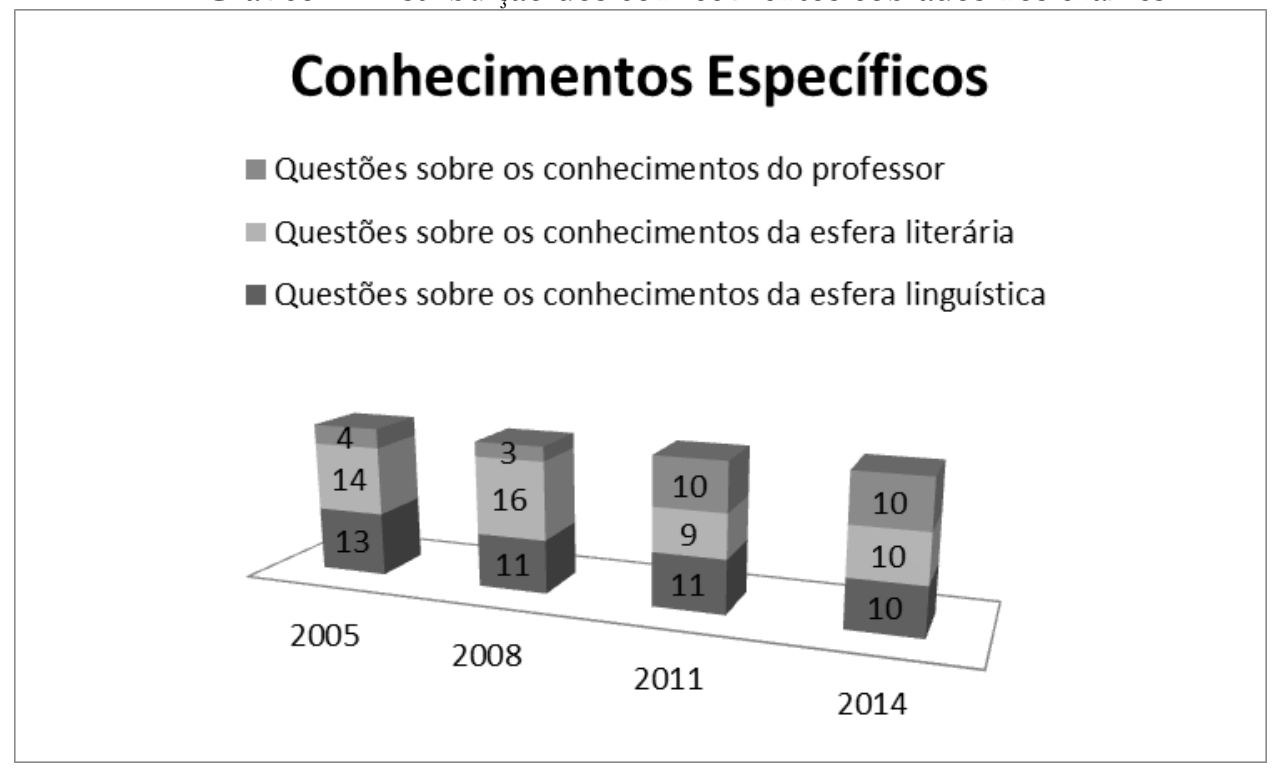

Fonte: Análise das provas do ENADE de 2005, 2008, 2011 e 2014.

Neste artigo, analisaremos as questões que classificamos como pertencentes à esfera literária. Com o universo de dados selecionados, identificamos os temas presentes nas questões elaboradas, a partir disto verificamos como tais temas foram trabalhados.

Nesta pesquisa de natureza mista, segundo Creswell (2007), num primeiro momento, o dado quantitativo foi importante, pois informou a frequência com que cada tema foi trabalhado em cada edição do ENADE. A partir da relação entre o dado quantitativo e o qualitativo foi possível fazer inferências sobre o impacto deste exame na formação do professor, quais conteúdos são valorizados, quais são desvalorizados (excluídos) e que tipo de perfil profissional tais exames disseminam.

\section{A formação do professor de literatura: o que o ENADE valoriza?}

É preciso compreender que toda avaliação também precisa ser avaliada, uma vez que a seleção curricular que a integra não é neutra, ela reflete o que cada sociedade considera importante para um professor e influenciará o ensino desse componente curricular.

Alguns meses antes da aplicação do exame, o INEP (Instituto Nacional de Estudos e Pesquisas Educacionais Anísio Teixeira) divulga uma portaria que o 
regulamenta, fazendo uma seleção dos conteúdos que serão cobrados na prova. A exemplo dessa prática, reproduzimos abaixo a listagem de conteúdos da prova do ano de 2005:

Estudos literários:

Conceitos, funções, valores, gêneros e periodização da literatura. Texto, contexto e intertextualidade. A singularidade da produção literária e inter-relações com outros sistemas culturais e semióticos. Literatura e recepção. As questões de estudos literários deverão enfocar, sem exclusividade, os seguintes autores e obras:

poesia - Cláudio Manoel da Costa, Gonçalves Dias, Manuel Bandeira, Carlos Drummond de Andrade, João Cabral de Mello Neto, Oswald de Andrade, Cecília Meireles, Jorge de Lima, Ana Cristina César, Camões (lírico), Bocage, Fernando Pessoa, Baudelaire (Asflores do mal);

prosa - Aluísio de Azevedo - O mulato; Machado de Assis - Esaú e Jacó; Guimarães Rosa - Grande sertão: veredas; Graciliano Ramos - São Bernardo; Clarice Lispector - Laços de família; Maria Carolina de Jesus - Quarto de despejo; Lygia Fagundes Telles - A noite escura e mais eu; Eça de Queiroz - Os Maias; José Saramago - O ano da morte de Ricardo Reis; Gabriel García Márquez - Cem anos de solidão; Jorge Luis Borges - Ficçoes; Gustave Flaubert - Madame Bovary; Miguel de Cervantes - Dom Quixote; Émile Zola - Germinal; José Luandino Vieira - Luuanda; teatro - Ariano Suassuna $-O$ auto da compadecida; William Shakespeare - Hamlet. (BRASIL, 2005, p. 05).

A prova do ENADE/2008, no Componente Específico da área de Letras, adotou como referencial os seguintes conteúdos:

2. Estudos literários:

2.1. conceitos de literatura e cultura;

2.2. texto, contexto e intertextualidade;

2.3. especificidade da linguagem literária;

2.4. inter-relações da literatura com outros sistemas culturais e semióticos;

2.5. literatura e recepção.

3. Formação profissional:

3.1. teorias de aquisição de língua materna;

3.2. teorias e métodos de ensino e aprendizagem de literatura e de língua materna;

3.3. tecnologias da informação e da comunicação;

3.4. ensino reflexivo.

As questões de estudos literários deverão enfocar os seguintes autores e obras:

I. Poesia:

a) Castro Alves;

b) Manuel Bandeira;

c) Carlos Drummond de Andrade;

d) João Cabral de Mello Neto;

e) Mário de Andrade;

f) Cecília Meireles;

g) Jorge de Lima;

h) Ana Cristina César;

i) Camões (lírico);

\footnotetext{
${ }^{1}$ Publicado primeiramente pela Portaria INEP no ${ }^{\circ}$ 175, de 24 de agosto de 2005

Publicada no Diário Oficial de 26 de agosto de 2005, seção 1, pág. 63. (BRASIL, 2005b)
} 
j) Fernando Pessoa;

k) Baudelaire (As flores do mal).

II. Prosa:

a) José de Alencar - Senhora;

b) Aluísio de Azevedo - O cortiç;

c) Machado de Assis - Quincas Borba;

d) Guimarães Rosa - Primeiras Histórias;

e) Graciliano Ramos - Vidas secas;

f) Clarice Lispector - Hora da Estrela;

g) Jorge Amado - Capitães da Areia;

h) Lygia Fagundes Telles - As horas nuas;

i) Eça de Queiroz - Primo Basílio;

j) José Saramago - Memorial do Convento;

k) Gabriel García Márquez - $O$ amor nos tempos do cólera;

1) Júlio Cortázar - Contos completos;

m) Gustave Flaubert - Madame Bovary;

n) Miguel de Cervantes - Dom Quixote;

o) Émile Zola - Germinal;

p) Pepetela (Artur Carlos Maurício Pestana dos Santos) - Mayombe;

III. Teatro

a) Ariano Suassuna - O santo e a porca;

b) Dias Gomes - O pagador de promessas;

c) William Shakespeare - Romen e Julieta. (BRASIL, 2008², p.16)

Art. $7^{\circ}$ A prova do Enade 2011, no componente específico da área de Letras, tomará como referencial os seguintes conteúdos curriculares:

I - Estudos lingüísticos:

a) formação histórica interna e externa da língua portuguesa;

b) fonologia, morfologia e sintaxe da língua portuguesa;

c) aspectos lexicais, semânticos, pragmáticos e discursivos da língua portuguesa;

d) aquisição da linguagem oral e escrita;

e) processos de leitura e produção de textos;

f) sociolingüística;

g) psicolingüística;

h) lingüística textual e análise do discurso;

i) gêneros do discurso.

II - Estudos literários:

a) conceitos de literatura e cultura;

b) texto, contexto e intertextualidade;

c) especificidade da linguagem literária;

d) períodos literários;

e) inter-relações da literatura com outros sistemas culturais e semióticos;

f) literatura e recepção.

III - Formação profissional:

a) teorias de aquisição e de aprendizagem de língua materna;

b) métodos de ensino de língua materna;

c) teorias e métodos de ensino de literatura;

\footnotetext{
${ }^{2}$ Publicado primeiramente pela Portaria Inep n ${ }^{\circ} 131$ de 07 de agosto de 2008. Publicada no Diário
} Oficial de 11 de agosto de 2008, Seção 1, p. 12 (BRASIL, 2008b) 
d) tecnologias da informação e da comunicação;

e) ensino reflexivo.

Parágrafo único. As questões de estudos literários deverão enfocar os seguintes autores e obras:

I - Poesia:

a) Tomás Antônio Gonzaga;

b) Manuel Bandeira;

c) Carlos Drummond de Andrade;

d) Ferreira Gullar;

e) Oswald de Andrade;

f) Cecília Meireles;

g) Jorge de Lima;

h) Hilda Hilst

i) Adélia Prado;

j) Bocage;

k) Fernando Pessoa.

II - Prosa:

a) José de Alencar - Lucíola ;

b) Adolfo Caminha - Bom crioulo;

c) Machado de Assis - Memorial de Aires;

d) Guimarães Rosa - Miguilim;

e) Érico Veríssimo - Um certo capitão Rodrigo;

f) Clarice Lispector - Uma aprendizagem ou o livro dos prazeres;

g) Jorge Amado - Capitães da Areia;

h) Luiz Vilela - Tarde da noite;

i) Eça de Queiroz - As cidades e as serras;

j) José Saramago - Ensaio sobre a cegueira;

k) Gabriel García Márquez - Cem anos de solidão;

l) Mia Couto - Terra sonâmbula;

m)Júlio Cortázar - Contos completos;

n) Gustave Flaubert - Madame Bovary;

o) Miguel de Cervantes - Dom Quixote;

p) Émile Zola - Germinal;

q) Pepetela (Artur Carlos Maurício Pestana dos Santos) - Mayombe.

III - Teatro

a) Jorge Andrade - Vereda da salvação;

b) Dias Gomes - O pagador de promessas;

c) Moliere - Dom Juan [...]. (BRASIL, 2011, p. 09)

Em razão de uma série de críticas recebidas, a partir do exame de 2014, a seleção curricular ficou menos específica, deixou de citar nominalmente autores e selecionar obras, conforme é possível observar nos excertos da portaria 258 (2014).

Art. $7^{\circ}$ A prova do Enade2014, no componente específico da área de Letras, de Letras, tomará como referencial os seguintes conteúdos curriculares: (...)

II - Estudos literários:

a) conceitos de literatura e cultura;

b) especificidades da linguagem literária;

\footnotetext{
${ }^{3}$ Publicado primeiramente pela Portaria Inep no 222 de 26 de julho de 2011 Publicada no Diário Oficial de 27 de julho de 2011, Seção 1, págs. 18 e 19. (BRASIL, 2011b).
} 


\section{Revista \\ ${ }_{A}$ Cor das Letras}
c) teorias críticas da Literatura;
d) gêneros literários (da Antiguidade à Contemporaneidade);
e) movimentos literários;
f) formação do cânone e do anticânone;
g) manifestações populares da Literatura;
h) inter-relações da Literatura com outros sistemas culturais e semióticos. (...) (BRASIL, 2014 $4^{4}$, p. 35)

Ao elaborar um rol de conhecimentos a ser cobrado no exame, o ENADE evidencia o seu objetivo de controlar o que é trabalhado no ensino superior, desta forma exerce uma pressão às instituições de ensino, sobretudo às instituições particulares que utilizam os seus resultados como "publicidade". O estreitamento curricular e a cobrança exercida pelo ENADE reforçam o efeito retroativo citado por Scaramucci (2004), desta forma a avaliação está determinando o que representa a "qualidade" de um curso. Mesmo sem especificar autores e obras, a ideia de estreitamento curricular continua.

A fim de compreender melhor este estreitamento curricular, realizamos um levantamento dos autores/teóricos que foram citados nos exames analisados:

Quadro 01. Autores mais citados nas questões pertencentes à esfera literária

\begin{tabular}{|c|c|c|c|}
\hline 2005 & 2008 & 2011 & 2014 \\
\hline Antonio Candido & $\begin{array}{l}\text { Antonio } \\
\text { Candido }\end{array}$ & Grice & Saraiva, A. J. \\
\hline Bakhtin/Volochinov & Leonardo Boff & $\begin{array}{l}\text { Afranio } \\
\text { Coutinho }\end{array}$ & Bakhtin/Volochinov \\
\hline José G. Merquior & Eliana Yunes & $\begin{array}{l}\text { Norma } \\
\text { Goldstein }\end{array}$ & Rodrigues, A.D. \\
\hline $\begin{array}{l}\text { Antonio Candido e } \\
\text { José } \\
\text { Castelo }\end{array}$ & $\begin{array}{lr}\text { Maria } & \text { Teresa } \\
\text { Esteban } & \mathrm{e} \\
\text { Edwiges } & \text { Zaccus }\end{array}$ & Aguiar e Silva & Palácio, A. \\
\hline Jorge Luis Borges & Juliane Corrêa & Clécio Bunzen & Miranda, G \\
\hline Hugo Friedrich & $\begin{array}{l}\text { Maria } \quad \text { C. } \\
\text { Campos }\end{array}$ & $\begin{array}{l}\text { Anne Marie } \\
\text { Chartier }\end{array}$ & Serafim, L \\
\hline Eça de Queirós & $\begin{array}{l}\text { Antoine } \\
\text { Campagnon }\end{array}$ & Umberto Eco & Oilnto, H.K. \\
\hline Cândido Portinari & Samira Chalub & Manuel Bandeira & Duarte, I e Leiria, I \\
\hline
\end{tabular}

${ }^{4}$ Publicada primeiramente pela Portaria No 258, De 2 De Junho De 2014, (BRASIL, 2014b) 


\begin{tabular}{|c|c|c|c|}
\hline Oswald de Andrade & $\begin{array}{l}\text { Roberto } \\
\text { Schwarz }\end{array}$ & Cecília Meireles & Bronckart, J.P. \\
\hline $\begin{array}{l}\text { Carlos Drummond } \\
\text { de Andrade }\end{array}$ & $\begin{array}{l}\text { Carlos } \\
\text { Drummond de } \\
\text { Andrade }\end{array}$ & $\begin{array}{l}\text { Carlos } \\
\text { Drummond de } \\
\text { Andrade }\end{array}$ & Waterson, C. \\
\hline Graciliano Ramos & $\begin{array}{l}\text { Graciliano } \\
\text { Ramos }\end{array}$ & $\begin{array}{l}\text { Vinicius de } \\
\text { Moraes }\end{array}$ & Silva, M.C. \\
\hline Machado de Assis & $\begin{array}{l}\text { Machado de } \\
\text { Assis }\end{array}$ & Chico Buarque & Júlio Cortázar \\
\hline Guimarães Rosa & Guimarães Rosa & Guimarães Rosa & Rubem Braga \\
\hline Charles Baudelaire & $\begin{array}{l}\text { Charles } \\
\text { Baudelaire }\end{array}$ & Gilberto Gil & Travaglia, L. C. \\
\hline \multirow[t]{8}{*}{ Manuel Bandeira } & $\begin{array}{l}\text { Aluísio de } \\
\text { Azevedo }\end{array}$ & Manuel Bandeira & Heitor, M. \\
\hline & Clarice Lispector & Cecília Meireles & Griebler, G. T \\
\hline & Émile Zola & & $\begin{array}{l}\text { Paz, A.N.; Pimentel, } \\
\text { FSC; Barros T }\end{array}$ \\
\hline & $\begin{array}{l}\text { João Cabral de } \\
\text { Melo Neto }\end{array}$ & & Geraldi, J. W. \\
\hline & Cecília Meireles & & Travaglia, L. C. \\
\hline & Fernando Pessoa & & Heitor, M. \\
\hline & Dias Gomes & & Griebler, G. T \\
\hline & Luiz de Camões & & \\
\hline
\end{tabular}

Fonte: Análise das provas do ENADE de 2005, 2008, 2011 e 2014

Os dados acima relacionados apontam que Antonio Candido e Bakhtin foram os dois teóricos mais citados no exame. No ENADE 2008, houve um maior número de autores literários e um menor número de teóricos, o que resulta num equilíbrio do número de textos em cada edição do exame. Os autores literários mais citados nas quatro edições analisadas foram: Carlos Drummond de Andrade e Guimarães Rosa, seguidos de Graciliano Ramos, Machado de Assis, Cecília Meireles e Manuel Bandeira que apareceram em duas edições do exame. $\mathrm{O}$ autor de literatura estrangeira 
mais cobrado no exame foi Charles Baudelaire, citado também em duas edições da prova.

Outra tendência que podemos identificar é a prevalência de textos de autores e teóricos escritos entre os séculos XIX e XX. Momentos importantes da nossa literatura como o romantismo ou o pós-modernismo não foram cobrados em nenhum momento, já que as referências se situam entre o realismo e o modernismo. A única exceção foi a alusão a uma produção literária de Luís Vaz de Camões, datada do século XVI.

Das questões que trabalham com a leitura a maioria pertence à esfera literária, pensando na definição de Bakhtin (2003), teríamos uma maior presença do gênero secundário. Nos gêneros secundários, foram cobrados diferentes tipos de texto:

Gráfico 02. Tipos de textos encontrados no ENADE

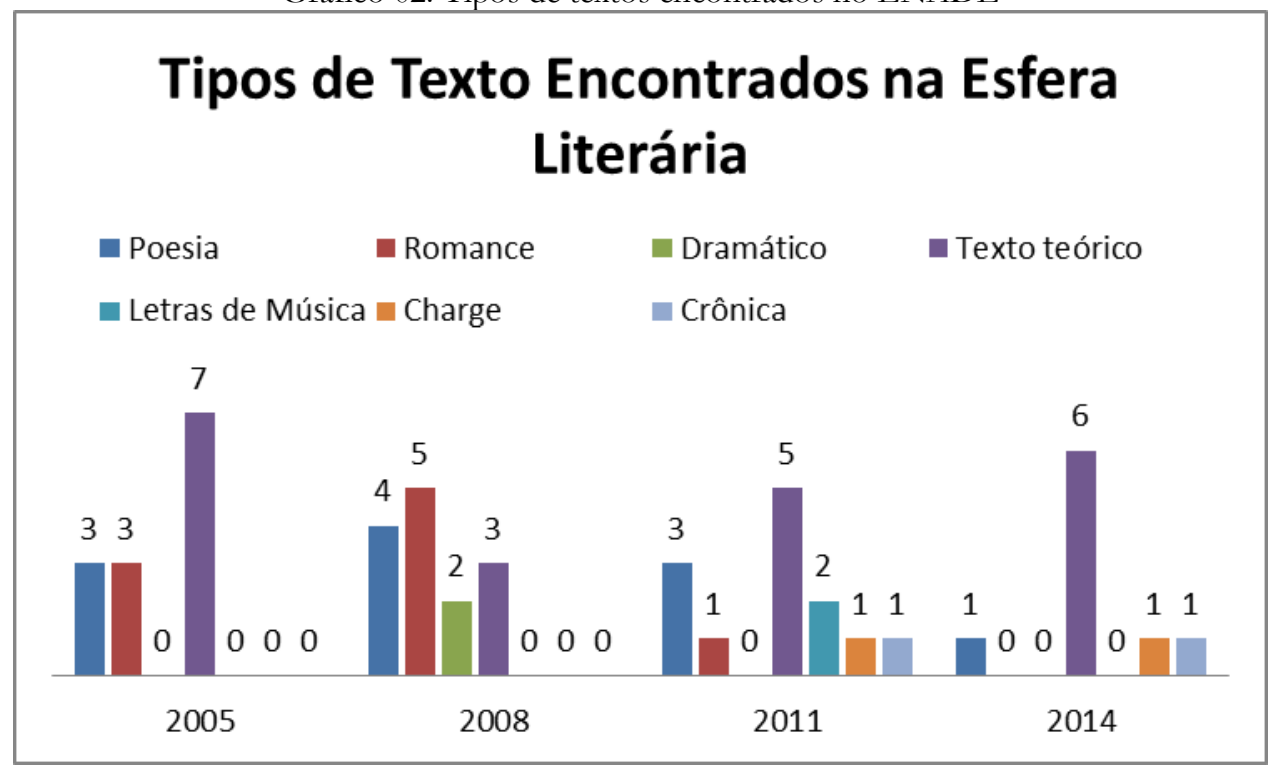

Fonte: Análise das provas do ENADE de 2005, 2008, 2011 e 2014.

A partir das informações coletadas, é possível apontar algumas tendências: trata-se de uma prova essencialmente de teoria literária e não de literatura, há mais textos de teóricos que discutem e analisam literatura do que dos próprios autores. Os textos teóricos foram os mais cobrados nos anos de 2005, 2011 e 2014, a única exceção foi o ENADE de 2008.

Uma questão que nos chamou a atenção foi a número 31:

Texto I. O termo “adaptar" está presente, hoje, em muitos setores da vida das pessoas: na adaptação escolar de uma criança, na adaptação de um romance para um filme ou na adaptação de objetos, instrumentos ou textos literários para outros destinatários que não os originais. Segundo o dicionário Aurélio, adaptar significa "ajustar, acomodar, adequar". [...] Essa adequação de comportamentos, objetos, instrumentos ou textos, de uma maneira geral, configura uma prática problematizada porque, justamente, envolve dois sujeitos: "o que faz" e aquele "para quem se faz", dados os diferentes pontos de 
vista do "emissor" e do "receptor" do produto final. A preocupação primeira do sujeito adaptador deverá ser a de assumir o lugar do outro, a fim de melhor executar sua tarefa. Essa postura, no entanto, nem sempre é garantia de um resultado final satisfatório para o público-alvo. [...] No entanto, o artifício pode configurar uma solução, à medida que faculta à criança o acesso a objetos ou artefatos não destinados, inicialmente, a ela. BÖHM, G. H. Peter Pan para crianças brasileiras: adaptação de Monteiro Lobato para a obra de James Barrie. In: CECCANTINI, J. L. (Org.) Leitura e Literatura infanto-juvenil: Memória de Gramado, São Paulo: Cultura Acadêmica; Assis: ANEP, 2004, p. 58-71.

Texto II $\mathrm{E}$ foi, provavelmente, no bojo de um de seus projetos previamente combinados com Octales, da Companhia Editora Nacional, que, em 1936, [Monteiro Lobato] lança seu D. Quixote das crianças. Nesse livro, encontra-se um projeto de leitura, de tradução e adaptação. E o leitor de hoje - em particular, o educador preocupado com questões de leitura - pode encontrar, nesse Quixote, respostas para questões que permeiam seu dia a dia escolar e que abrangem desde a crucial pergunta "que livro indicar?" até a questão de os clássicos serem ou não adequados a tal ou qual faixa etária. LAJOLO, M. Do mundo da leitura para a leitura do mundo. São Paulo: Ática, 1994, p. 97 (com adaptações). Considerando os textos I e II, avalie as seguintes afirmações

I. Os textos literários, quando adaptados para se adequarem ao leitor iniciante, revelam o caráter didático e utilitário, que os liga a um ramo específico do conhecimento (valores morais, tópicos gramaticais, fatos históricos, entre outros).

II. A existência de um projeto ficcional levado a termo pelo autor que se propõe efetuar a adaptação de um texto literário pode dotar a adaptação de uma função mediadora na formação de leitores.

III. O processo de adaptação, quando atinge a motivação estética da literatura e o repertório do destinatário, tende a promover a interação entre leitor e texto, sujeito e objeto de leitura.

IV. O processo de adaptação de textos literários implica a redução e o empobrecimento da obra original, causando danos à linguagem literária e aos recursos estilísticos da obra. Está correto apenas o que se afirma em

A I e III.

B I e IV.

C II e III.

D I, II e IV.

E II, III e IV (ENADE, 2014, p. 24).

Tal questão aborda a temática da adaptação literária que, de acordo ao expressado, não significa, necessariamente, um empobrecimento do texto literário. A resposta correta para tal questão é a C (afirmação II e III são corretas), o que valoriza a interpretação positiva sobre as adaptações, o próprio texto da Lajolo utilizado na questão é uma adaptação. Tal visão não é um consenso na área, adotá-la como uma verdade, mesmo que baseada nos textos citados, é propagar uma visão tendenciosa sobre uma temática controversa, muitos estudantes podem ter assinalado uma resposta incorreta em razão do tema ser controverso.

Para Candido (2008), a literatura não pode ser entendida à margem da sociedade, não se pode ignorar o vínculo entre a obra e o ambiente. Para o autor, a obra literária é permeada por um conjunto de fatores sociais que atuam sobre a formação da mesma, além da influência que ela exerce no meio social a que pertence. Desta forma, o exame considerar correta a opção que legitima a postura do professor 
em escolher adaptações literárias em substituição ao texto literário de origem é algo controverso, pois dificilmente um texto fragmentado/adaptado manterá o mesmo diálogo com seu contexto e/ou com seu leitor.

Da mesma forma, o próprio trabalho com a linguagem será alterado, para Eagleton (2006), uma característica importante da literatura é o emprego da linguagem de uma forma peculiar, trata-se de uma linguagem que chama a atenção sobre si mesma, num texto adaptado/fragmentado esta construção será secundarizada. Tais apontamentos reforçam a ideia de que a adaptação literária é um assunto polêmico para a área, portanto cobrar do futuro professor uma resposta positiva sobre tal tema como se o mesmo fosse um consenso é uma postura no mínimo questionável, por isso a importância de conhecermos o que o exame está cobrando.

\section{O QUE NÃO COMPARECE NO ENADE}

Reiterando o fato já ressaltado aqui de que toda escolha curricular é baseada em aspectos políticos e ideológicos, cumpre manifestar que as escolhas bibliográficas e de conteúdo do ENADE não correspondem com o que se tem desenvolvido mais recentemente no campo da pesquisa em Letras, o que evidencia uma disposição mais conservadora do grupo que orienta o exame. Nessa mesma esteira, vale ressaltar que as listas de conteúdos fixada em títulos de obras e autores apontam para uma restrição sobre o entendimento do que vem a ser conhecimento literário, isto é, afirma-se, mesmo que indiretamente, um conceito de literatura atrelado unicamente ao cânone.

Atualmente, porém, o conceito de obra literária se expande cada vez mais, o que tem criado reflexões mais complexas sobre os limites do que é ou não literário. Compagnon (2010), autor de grande relevância nos estudos literários e não mencionado na lista do ENADE, discute em $O$ demônio da teoria: literatura e senso comum, as dificuldades de se delimitar uma concepção final de literatura, dado às circunstâncias em que ela é produzida e à própria multiplicidade de formas de sua apresentação.

Entendemos que, devido às configurações múltiplas que a literatura vem assumindo, ao menos desde a passagem do século XIX para o XX, um elemento de grande relevância a ser observado num exame como o ENADE refere-se à profundidade e à complexidade da compreensão de literatura que os alunos, ao final do curso de Letras, apresentam. Parece-nos que, por meio da checagem de conhecimento de alguns poucos autores do cânone literário, pouco ou nada se poderá verificar a respeito do entendimento que os alunos desenvolveram sobre fenômenos literários mais recentes - como a cultura hip-hop -, mais populares como a produção de cordéis - ou multimodais - como os quadrinhos, a poesia sonora, a poesia visual e cibernética entre outros.

Nesse sentido, tendo em vista que o trabalho do professor de literatura será a negociação dos saberes, torna-se profundamente relevante que o licenciado em 
Letras tenha uma formação que, para além do repertório do cânone, capacite-o a, de forma ponderada e baseada em conhecimentos teóricos, avaliar obras pouco conhecidas, mesmo aquelas trazidas pelos alunos, não com a finalidade de julgá-las, mas com a possibilidade de ensinar a analisá-las e a problematizá-las.

$\mathrm{Na}$ interface entre os conhecimentos literários e os pedagógicos, o exame também passa ao largo da pesquisa sobre ensino de literatura e formação de leitores. Não afere, portanto, os conhecimentos teórico-metodológicos que o aluno deve desenvolver ao longo do curso para que possa habilitar-se ao ensino. Teóricos como Isabel Solé, Tereza Colomer e Vincent Jouve não são mencionados na lista do exame.

Ainda no campo dos estudos teóricos, apesar de o exame trazer autores de máxima relevância, como é o caso de Candido e Bakhtin, deixa de abordar tendências mais recentes e de grande relevância, como a Estética da Recepção, de Jauss, e a Teoria do Efeito, de Iser, discussões de extrema relevância para que o aluno de Letras tenha condições de refletir a respeito do lugar do leitor na constituição da literatura.

Outra tendência de grande relevância na atualidade que não comparece nas listas do ENADE é a dos Estudos Culturais. A ausência de autores como Paul Zumthor, que discute a relevância da oralidade na performance literária, sobretudo hoje, cujo cenário cultural passa por uma multiplicidade de objetos que se dão a ler do oral ao cibernético -, parece-nos uma redução no entendimento do que vem a ser literatura e seu ensino.

Por fim, não tão recentes, mas não menos relevantes e nada mencionados nos programas do ENADE, são os estudos da Semiótica. Desde os mais tradicionais no campo, como Barthes e Greimas, até os mais contemporâneos, como Eric Landowski, da sociossemiótica, nenhuma menção se faz a esse campo de investigação da linguagem, o que revela uma significativa opção por não considerar o contemporâneo, o multissemiótico, as expressões mais recentes da literatura.

\section{CONSIDERAÇÕES FINAIS}

O ENADE tem selecionado as mesmas perspectivas teóricas nas quatro edições analisadas, o que contradiz a diversidade pregada pelas DCN que, de uma maneira geral, orientam o que o curso deve trabalhar, buscando integrar diferentes conhecimentos da área literária e linguística. O ENADE, ao enfatizar, nas quatro edições analisadas, os mesmos conteúdos, acaba por excluir autores e temas importantes (como Greimas, Barthes, Jauss, Iser entre outros), o que se mostra incoerente com a orientação oficial e com a própria proposta da avaliação: o discurso aponta para uma diversificação que o exame não realiza na prática.

Outro problema encontrado no ENADE é a divulgação do seu resultado na mídia, o qual aparece como um sinônimo da qualidade do ensino ofertado, o que serve de justificativa para muitas universidades formatarem os seus cursos com base 
no que o exame cobra. Desta forma, o ENADE tem um papel regulador do currículo do ensino superior, o que ultrapassa os objetivos declarados pela avaliação.

Um curso constituído a partir do ENADE negligenciará correntes literárias importantes e que ajudaram a construir a nossa história literária (como o romantismo e o pós-modernismo), não abordará as literaturas africanas e indígenas como constituidoras do nosso repertório cultural, e excluirá concepções teóricas importantes para o futuro professor (estética da recepção, semiótica, teoria do efeito, entre outras). Mais que isso, não permitirá que o egresso tenha uma formação que favoreça a sua autonomia na análise e na compreensão de obras que não façam parte do cânone.

Além disso, assumirá um ponto de vista analítico muito restrito, uma vez que este será baseado em poucas perspectivas analíticas, nenhuma delas muito recente ou de maior complexidade.

\section{REFERÊNCIAS}

AFONSO, A. J. Avaliação Educacional: Regulação e Emancipação: para uma sociologia das políticas avaliativas contemporâneas. São Paulo: Cortez, 2009

BAKHTIN, M. Estética da Criação Verbal. São Paulo: Martins Fontes, 2003

BARTHES, R. O rumor da língua. Tradução de Mario Laranjeira. São Paulo: Martins Fontes, 2004.

BARTHES, R. O praz̧er do texto. Tradução de j. Guinsburg. São Paulo: Perspectiva, 1999.

BRASIL. Lei $n^{\circ}$ 10.861, de 14 de abril de 2004. Institui o Sistema Nacional de Avaliação da Educação Superior-SINAES e dá outras providências. Diário Oficial da União, n. $\quad 72, \quad 2004 . \quad$ Disponível em : http://www.planalto.gov.br/ccivil_03/_ato2004-2006/2004/lei/110.861.htm Acesso em : 31 ago. 2019.

BRASIL. Diretrizes Curriculares Nacionais. 2001. Disponível em: http://portal.mec.gov.br/cne/arquivos/pdf/CES0492.pdf. Acesso em: 15/10/2013 BRASIL Portaria INEP no. 175, de 24 de agosto de 2005. Disponível em : http://download.inep.gov.br/download/enade/PORTARIAS_ENADE_2005/Letr as.pdf Acesso em 16 ago. 2018

BRASIL Portaria Inep $\mathrm{n}^{\circ} 131$ de 07 de agosto de 2008. Disponível em: http://download.inep.gov.br/download/superior/enade/Diretrizes\%20Enade/Dire trizes_Letras_\%20n_131.pdf Acesso em 16 ago. 2018

BRASIL Portaria Inep $\mathrm{n}^{\circ} 222$ de 26 de julho de 2011. Disponível em: http://download.inep.gov.br/educacao_superior/enade/legislacao/2011/diretrizes/ diretrizes_letras_n_222.pdf Acesso em 16 ago. 2018

BRASIL Portaria $n^{\circ} 258$, de 2 de junho de 2014. Disponível em: http://download.inep.gov.br/educacao_superior/enade/legislacao/2014/portarias_ diretrizes_ns_233_a_266_de_02_de_junho_2014.pdf_Acesso em 16 ago. 2018 CANDIDO, A. Literatura e Sociedade. 10a. Ed. São Paulo: ouro sobre azul, 2008. 
COLOMER, T. Andar entre livros: a leitura literária na escola. Tradução de Laura Sandroni. São Paulo: Global, 2007.

COMPAGNON, A. O demônio da teoria: literatura e senso comum. Tradução Cleonice Paes Barreto Mourão, Consuelo Fontes Santiago. Belo Horizonte: UFMG, 2010.

CRESWELL, J. W. Projeto de Pesquisa: métodos qualitativo, quantitativo e misto.. Porto Alegre, RS: Artmed, 2007

EAGLETON, T. Teoria da Literatura: uma introdução. São Paulo: Martins Editora, 2006

ISER, W. A leitura em questão: uma teoria do efeito estético. V1.2. Tradução de Johanes Kretschner. São Paulo: 34, 1999.

JAUSS, H. R. A bistória da literatura como provocação à teoria da literatura. Tradução de Sérgio Tellaroli. São Paulo: Ática, 1994.

JOUVE, V. A leitura. Tradução de Brigitte Hervot. São Paulo: Unesp, 2002.

LANDOWSKI, E. Sociossemiótica: uma teoria geral do sentido. Galaxia, São Paulo, n. 27, p. 10-20, jun. 2014. http://dx.doi.org/10.1590/1982-25542014119609.

MADAUS, G. F. The Influence of Testing on the Curriculum. In: TANNER, L N.

Critical Issues In Curriculum: Eighty-Seventh Yearbook of the National Society for the Study of Education. Chicago, Illinois: NSSE, 1988

SCARAMUCCI, M. V. R.. Efeito retroativo da avaliação no ensino/aprendizagem de línguas: o estado da arte. In: Trab. linguist. apl., Campinas, v. 43, n. 2, p. 203-226, Dec. 2004 Disponível em: http:/ /www.scielo.br/scielo.php?script=sci_arttext\&pid=S010318132004000200002\&lng=en\&nrm=iso Acesso 12 abril 2017. SOLÉ, I. Estratégias de leitura. Porto Alegre: Artmed, 1998.

STECHER, B. M. Consequences Of Large-Scale, High-Stakes Testing on School And Classroom Practice. In: Hamilton, L. S; Stecher, B. M; Klein, S.P. (editors) Making Sense of Test Based Accountability in Education. Santa Monica, CA, 2002 